\title{
GCU
}

Glasgow Caledonian

University

University for the Common Good

\section{Design and delivery of cloud computing syllabus for computing undergraduates}

Nazir, Sajid; Paterson, James H.; Hainey, Brian

Published in:

Proceedings of the 9th Computer Science Education Research Conference

DOI:

$10.1145 / 3442481.3442508$

Publication date:

2020

Document Version

Author accepted manuscript

Link to publication in ResearchOnline

Citation for published version (Harvard):

Nazir, S, Paterson, JH \& Hainey, B 2020, Design and delivery of cloud computing syllabus for computing undergraduates. in D Stikkolorum \& E Rahimi (eds), Proceedings of the 9th Computer Science Education Research Conference., 12, Association for Computing Machinery (ACM). https://doi.org/10.1145/3442481.3442508

\section{General rights}

Copyright and moral rights for the publications made accessible in the public portal are retained by the authors and/or other copyright owners and it is a condition of accessing publications that users recognise and abide by the legal requirements associated with these rights.

Take down policy

If you believe that this document breaches copyright please view our takedown policy at https://edshare.gcu.ac.uk/id/eprint/5179 for details of how to contact us. 


\section{Design and Delivery of Cloud Computing Syllabus for Computing Undergraduates}

\author{
Sajid Nazir \\ sajid.nazir@gcu.ac.uk \\ Glasgow Caledonian University \\ Glasgow, UK
}

\author{
James H. Paterson \\ james.paterson@gcu.ac.uk \\ Glasgow Caledonian University \\ Glasgow, UK
}

\author{
Brian Hainey \\ b.hainey@gcu.ac.uk \\ Glasgow Caledonian University \\ Glasgow, UK
}

\begin{abstract}
Cloud computing is a highly disruptive paradigm transforming the way we interact with technologies. Cloud platforms and services have become the predominant choice for any real-world storage and computation intensive applications such as Internet of Things (IoT), Big Data and Artificial Intelligence (AI), making it a must-have skill for undergraduates across many disciplines. Cloud technology, services and applications are evolving rapidly and it is challenging to design an academic syllabus that encompasses a comprehensive and up-to-date body of knowledge in an engaging way.

This paper describes our approach to designing a new module to provide a broad overview of Cloud Computing and practical skills in developing solutions using services offered by a cloud platform, in this case Amazon Web Services (AWS) for Computing undergraduate students at Glasgow Caledonian University (GCU), UK. We describe the rationale for the syllabus design and outline the lectures, practical activities and assessments that were developed. The practicals were designed to be executed on the AWS platform as bite-sized tasks providing hands-on learning to reinforce prior lecture content. The first syllabus delivery at GCU shows that the students performed well, found the content engaging and easy to assimilate, and had a fulfilling learning experience. The issues involved in using 'live' cloud platforms for teaching are also evaluated.
\end{abstract}

\section{CCS CONCEPTS}

- Social and professional topics $\rightarrow$ Computing education.

\section{KEYWORDS}

cloud computing, curriculum, student learning, artificial intelligence, pedagogy, microlearning, syllabus, cloud platforms, cloud services

\section{ACM Reference Format:}

Sajid Nazir, James H. Paterson, and Brian Hainey. 2020. Design and Delivery of Cloud Computing Syllabus for Computing Undergraduates. In CSERC '20: The 9th Computer Science Education Research Conference, October 19-20, 2020, Online Virtual. ACM, New York, NY, USA, 2 pages. https://doi.org/10. 1145/nnnnnnn.nnnnnnn

\section{INTRODUCTION}

Cloud computing provides access to virtually unlimited compute, network and storage resources over private networks and the Internet. This enables anytime, anywhere access to the computing resources with pay per use for the services. Cloud computing has become an essential skill for professionals [1]. Recognising the skills gap, academia has started to take measures to include these skills in their syllabi [2].

The cloud computing curriculum is evolving continuously [3] as new services are added by the Cloud Service Providers (CSPs). As a result it can be difficult to design and deliver a relevant and comprehensive syllabus that provides a high quality learning experience. This paper describes the approach and experience of design and delivery of cloud curriculum using AWS for the GCU Cloud Platform Development (CPD) module during academic year 201920 for an undergraduate class at Glasgow Caledonian University (GCU), UK.

The module design was guided by the findings of two ITiCSE working groups to which the authors of this paper contributed: a collection of resources helpful to design and teach a project-based model cloud curriculum identified through a survey [4]; and the work to identify cloud computing teaching material, and catalogue it according to the learning objectives into exemplar modules described in [5]. The major CSPs (AWS, Microsoft, Google and IBM) also have many education related initiatives aimed at academia. The strategies for teaching cloud computing and its impact on computer science education is described in [6].

Microlearning is a technique based on micro-content comprising of small tasks [6] that can be completed in a few minutes, and can relate to training, teaching, and assessment. Our cloud curriculum makes use of Microlearning, also referred as 'bite-sized', a technique in which the educational process is delivered as small chunks [6].

The rest of the paper is structured as follows: Module design is described in Section 2. Module material is covered in Section 3. Section 4 provides details of the evaluation. The conclusion is provided in Section 5.

\section{MODULE DESIGN}

The first and most important decision was the choice of the cloud platform. AWS was chosen being the largest cloud platform with mature technologies [2, 7]. AWS platform development supports many programming languages. The preferred language on AWS is Python and the preferred Software Development Kit (SDK) is Boto3 [8]. AWS allows access to a cloud based IDE accessible through a web browser [9].

The AWS Educate program provides access to many useful learning and teaching resources, and usage credit for educators and students [10]. The credit can be used to get free access to the AWS cloud environment.

A large task in lab or coursework can be overwhelming for students. Students learn best with smaller tasks [6] and a supportive learning environment. 


\section{MODULE MATERIAL}

With so many services provided by AWS, only a representative subset can be covered in an undergraduate course [7]. In order to incorporate the curriculum design goals, the topics that were included are as shown in Table 1.

\begin{tabular}{|c|l|}
\hline Week & Lecture Topic \\
\hline 1 & Introduction to Cloud Computing \\
\hline 2 & Service Models and Architecture \\
\hline 3 & Virtualisation and Containerisation \\
\hline 4 & Serverless Computing and Web Services \\
\hline 5 & Data in the Cloud \\
\hline 6 & Cloud Platform Applications - Machine Learning and Big Data \\
\hline 7 & Security for Cloud Applications \\
\hline 8 & Cloud Platform Applications - IoT and DevOps \\
\hline 9 & Consistency and Scaling \\
\hline 10 & Reliability and Scalability \\
\hline 11 & Latest Trends in Cloud Computing \\
\hline 12 & Revision \\
\hline
\end{tabular}

Table 1: Lecture topics schedule designed to aid in coursework release, conduct and marking.

Tutorial sessions were used to cover problem solving exercises and to allow discussion on theoretical concepts covered in the lectures. Tutorials were also used to discuss any class-wide issues and for exam preparation.

The lab exercises [11] were designed to support the lecture material covered in the class. This helped to reinforce the important concepts and skills [6].

\section{EVALUATION}

The assessments comprised of an exam and a coursework. The overall architecture of the coursework application to be developed is shown in Fig 1. The students performed well in both the exam and coursework component.

The feedback provided by the students was very positive and the students seemed to enjoy the way that the lecture and lab material were designed and conducted.

The overall enjoyment of the module was rated as 'Extremely enjoyable' by $5 \%$, 'Very enjoyable' by $35 \%$ and 'Somewhat enjoyable' by $60 \%$ of the respondents.

The pace of learning in the module was rated as 'Just about right' by $95 \%$, and 'Too slow' by $5 \%$ of the respondents.

Almost all respondents found the lab structure, descriptiveness, and organisation to be very helpful. Two comments were, "Core concepts are explained and exemplified extremely well, gives a good idea of what the subject is all about" and "Labs are very well structured, easy to digest and follow with good further reading available".

\section{CONCLUSION}

Cloud computing has experienced a significant growth in its relevance for academia and industry. It is a step change from the usual way that computation and storage resources are used. The
Figure 1: The application architecture for the coursework.

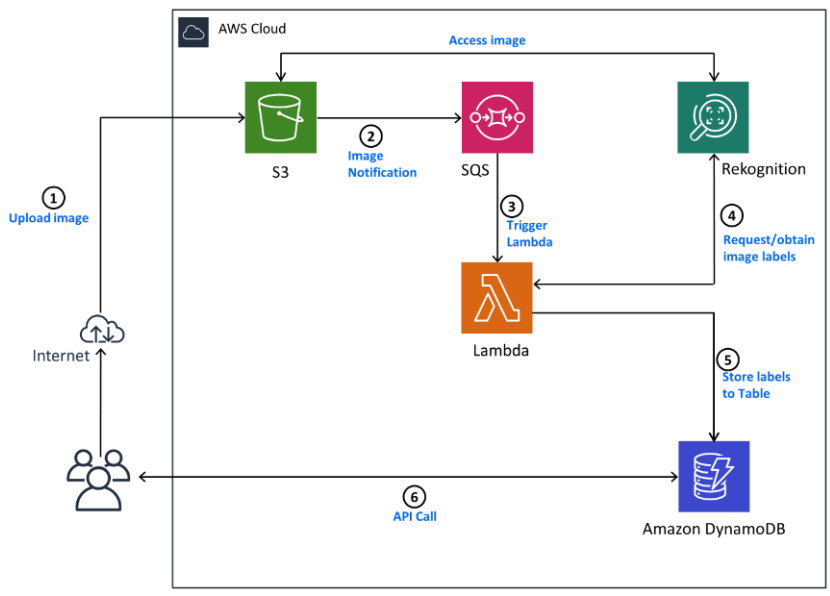

current study-from-home education environments created due to COVID-19 makes cloud platform an enabler technology due to its virtually unlimited computation and storage resources, and access from anywhere using only a web browser.

This paper described the design and delivery of a cloud computing module based on the latest technologies to provide a balanced exposure to the students. The syllabus aimed to create a supportive yet challenging environment for teaching cloud computing concepts using the AWS platform.

The trajectory of cloud adoption in higher education seems to indicate that similar to programming skills, it will became a must have skill for all disciplines being taught as a module at different levels with progressive levels of difficulty.

\section{REFERENCES}

[1] H. P. Breivold and I. Crnkovic. Cloud computing education strategies. In 2014 IEEE 27th Conference on Software Engineering Education and Training (CSEE\&T), pages 29-38. IEEE, 2014.

[2] M. Suhail Rehman, Jason Boles, Mohammad Hammoud, and Majd F. Sakr. A cloud computing course: From systems to services. In SIGCSE '15: Proceedings of the 46th ACM Technical Symposium on Computer Science Education, pages 338-343. ACM, 2015.

[3] Scott Campbell. Teaching cloud computing. Computer, 49(9):91-93, 2016.

[4] D. Foster, L. White, D. C. Erdil, J. Adams, A. Argüelles, B. Hainey, H. Hyman, G. Lewis, S. Nazir, V. Nguyen, M. Sakr, and L. Stott. Toward a cloud computing learning community. In ITiCSE-WGR '19:Proceedings of the Working Group Reports on Innovation and Technology in Computer Science Education, pages 143-155. ACM, 2018.

[5] J. Adams, B. Hainey, L. White, D. Foster, N. Hall, M. Hills, S. Hooshangi, K. Kuber, S. Nazir, M. Sakr, L. Stott, and C. Taglienti. Cloud computing curriculum: Developing exemplar modules for general course inclusion. In ITiCSE '20: Proceedings of the 2020 ACM Conference on Innovation and Technology in Computer Science Education, pages 510-511. ACM, 2020.

[6] Luminiţa Giurgiu. Microlearning an evolving elearning trend. In Bulletin Scientific, volume 22, 2017.

[7] Dahai Guo and Anna Koufakou. A comprehensive and hands-on undergraduate course on cloud computing. In 2018 ASEE South-eastern Section Conference, 2018.

[8] Boto3 documentation. https://boto3.amazonaws.com/v1/documentation/api/ latest/index.html. [Online; accessed 19-July-2020].

[9] Cloud9. https://aws.amazon.com/cloud9/. [Online; accessed 19-July-2020].

[10] AWS Educate. https://aws.amazon.com/education/awseducate/. [Online; accessed 19-July-2020].

[11] Github repository. https://github.com/sajidnazir/CourseMaterialCloudComputing2019AWS-Labs. [Online ; accessed 21-Oct-2020]. 